Research Article

\title{
Research and Development of Civil Engineering Intelligent Structure System
}

\author{
Junkai Xie, Bo Gao $\mathbb{D}^{\text {, }}$, and Huamin Cheng \\ First Construction Engineering Limited Company of China Construction Third Bureau, Wuhan 430040, Hubei, China \\ Correspondence should be addressed to Bo Gao; gb2020@cscec.com
}

Received 24 September 2020; Revised 30 October 2020; Accepted 2 January 2021; Published 28 January 2021

Academic Editor: Sang-Bing Tsai

Copyright (c) 2021 Junkai Xie et al. This is an open access article distributed under the Creative Commons Attribution License, which permits unrestricted use, distribution, and reproduction in any medium, provided the original work is properly cited.

\begin{abstract}
With the rapid development of global civil engineering construction, the intelligent structural system of civil engineering has evolved into one of the current global frontier disciplines. The research on the intelligent structural system of civil engineering and the current development situation are analyzed, and the main problems are combined. Giving reasonable suggestions is of great significance to the country's vigorous development of civil engineering intelligent structure system. This paper designs a new type of three-dimensional fiber grating sensor, including the design of the matrix model and the design of fiber grating strain gauges. This new sensor can effectively measure three-dimensional space, greatly expanding the application range of fiber grating sensors. In this paper, the design lighting area of each light pipe is taken as a unit. Each unit is set with 4 measuring points at the center and the edge. Each measuring point reads 3 illuminance value parameters and records the average value. Based on the results and comprehensive consideration of the short board situation, the research conclusions and recommendations are put forward. The foundation wall with aerated concrete blocks as the wall material can meet the requirements of $50 \%$ energy saving for exterior wall buildings with external decoration and internal insulation mortar. Compared with the benchmark wall of $50 \%$ energy saving of external wall buildings, the heat transfer coefficient is reduced by $50.1 \%$, and the actual energy-saving effect of the wall can reach $75 \%$. Meet the requirements of $65 \%$ for the energy-saving effect of exterior wall buildings. This paper considers economic parameters, such as the investment cost of building insulation materials, energy-saving income, and investment recovery period, and establishes a calculation model for analyzing the economics of insulation materials. Based on the heat transfer model of the composite wall and the fuel energy combustion equation, greenhouse gas is an established calculation model for $\mathrm{CO}_{2}$ and $\mathrm{SO}_{2}$ emissions. Studies have shown that when considering the room temperature insulation performance of insulation materials, the time required for the side of the concrete slab with glass fiber felt and aerogel insulation materials is about 2022 and $3363 \mathrm{~s}$, respectively, indicating the fire resistance of aerogel insulation materials significantly better than fiberglass.
\end{abstract}

\section{Introduction}

In recent years, with the rapid development of the social economy and the continuous improvement of people's quality of life, energy consumption has gradually increased [1], of which building energy consumption accounts for about $40 \%$ of the total energy consumption of the whole society, so building energy saving is the key to achieving energy saving in the whole society field. Building energy efficiency is to reduce energy consumption as much as possible under the conditions of meeting the same needs of users or achieving the same purpose. Through the implementation of relevant energysaving design standards, the use of energy-efficient building materials, equipment, and products strengthens the operation management of construction equipment [2], thereby improving the thermal performance of the entire building and the efficiency of cooling and heating systems. Secondly, on the premise of meeting the requirements of building use and the quality of the indoor thermal environment, reduce the energy consumption of equipment cooling and heating, lighting, hot water supply system, and so forth; use energy reasonably and efficiently; and realize the overall energy saving of the building.

With the rapid development of civil engineering intelligent structural system, many teams began to study it. For example, Legatiuk et al.'s experiment prepared an aerogel concrete template with a regular shape and applied it to a fireproof experimental device [3]. Chowdhury and Dey 
produced the aerogel mortar by experiment and applied it to the structural wall in the French region. Secondly, the thickness and investment cost of the aerogel mortar were optimized based on the numerical model, which was effective when the same thermal insulation effect was achieved. Reduce its investment cost [4]. Manandhar et al. applied composite phase change wall panels to the walls and roofs of typical residential buildings. Using the outdoor weather data of the typical weather year as the external weather conditions, the numerical value of the energy-saving potential of phase change materials in residential buildings was simulated [5]. In the process of making an ordinary gypsum board, Zhang and Li directly mixed 21-22\% commercial grade butyl stearate to make a phase change energy storage gypsum board wall and compared it with the ordinary gypsum board wall without adding phase change material. It is concluded that the physical and mechanical properties of the phase change gypsum board wall are better than those of the ordinary gypsum board wall, and its energy storage/releasing ability has been increased by ten times [6].

In the process of studying intelligent structures in civil engineering, it is a good method to study the complex thermodynamics of SMA materials. For example, Abubaker et al. analyzed the stress-induced phase transformation in geometrically graded shape memory alloy samples through an analytical approach. First, in the two-dimensional framework, a partial differential equation (PDE) control system consisting of equilibrium equations, unstressed boundary conditions, and phase transition criteria is derived [7].

In this paper, the performance testing and screening of phase change materials are carried out, and the phase change materials suitable for the climatic characteristics of the hot summer and winter warm regions are selected. The heat transfer coefficient of the composite wall is tested by the variable temperature method to investigate the phase change energy storage, energy-saving effect of composite wall. This article studies the impact of performance parameters (degree days, wall thermal resistance) and economic parameters (material price) on the economic performance and environmental performance (greenhouse gas emissions) of aerogel insulation materials. Through the investigation of the subjective feelings of the case, this article truly reflects the evaluation of the lighting effect. Finally, the evaluation data of each case is analyzed and compared with the evaluation standard, and the conclusion of evaluation and analysis of lighting application effect is obtained.

\section{Research on Intelligent Structural System of Civil Engineering}

\subsection{Fiber Bragg Grating Monitoring Principle}

2.1.1. Principle of Demodulation. According to the known basic theory of fiber grating, the Bragg wavelengths $\lambda_{B}$ and $\Delta \lambda_{B}$ have a linear relationship, and the strain of the fiber grating sensor is transmitted through the interface between the package and the measured surface [8], so the actual reaction of the fiber grating sensor is the strain transmitted to the sensor, rather than the actual strain at the interface of the building, has a certain proportional relationship, and may change with changes in external factors such as temperature $[9,10]$.

For fiber Bragg gratings, the basic characteristics of the reflection spectrum are as follows:

$$
\lambda_{\max }=\left(1+\frac{\Delta n}{n_{\mathrm{eff}}}\right) \lambda_{B} .
$$

It can be seen from the above formula that the depth of refractive index modulation is affected by various factors, and its change will directly affect the center wavelength. When it becomes larger, the wavelength will shift to the long wave side. This phenomenon can be found through experimental observations $[11,12]$. In addition, due to the relative wavelength value, the offset is very small; that is, $n_{\text {max }} \ll n_{\text {eff }}$. When special conditions such as phase mismatch occur, the reflectance will be greatly reduced.

2.1.2. WDM Technology. Fiber Bragg Grating sensor network multiplexing technology covers a wide range, and the subject uses a combination of two methods of wavelength division and space division multiplexing. The most prominent advantage and the best value of fiber grating is that it can be connected in series or written in multiple fiber grating sensor arrays in the same fiber $[13,14]$. By embedding or pasting the sensor head on the structure or the surface or inside of the material to be measured, real-time monitoring of temperature and other physical quantities can be achieved. The light emitted by the broadband light source is incident through the demultiplexing device, forming a device combining wave division multiplexing and space division multiplexing, forming an array combining two FBGs, and feeding back the optical signal to the demultiplexing device for demodulation; thereby, realization can achieve the goal of wavelength-multiplexed optical signal demodulation one by one [15-18].

2.1.3. Light Source Equipment. The light source equipment used in the experiment is a Santec light source, which can provide a polarized light source with stable performance, which can effectively supply light to other spectrum analysis equipment, ensuring the smooth progress of the experiment $[19,20]$. The broadband detection light range generated by the light source is the measurement range of the experimental instrument. It uses the second-generation USB interface, which can effectively transfer data.

2.1.4. Spectrum Analyzer. The experiment uses the AQ6370D series high-precision spectrum analyzer, which has a fast measurement speed, the latest channel interface, and a strong spectrum analysis ability [21]. It is easy to operate and can greatly improve the measurement effect of $\mathrm{R} \& \mathrm{D}$ and production. It is quite popular in the market. It is very popular in the market because of its high cost performance with high cost performance [22, 23]. The main features of this series of spectrometers are as follows: wide 
wavelength range $600 \sim 1700 \mathrm{~nm}$, high wavelength accuracy error within $0.01 \mathrm{~nm}$, high wavelength resolution of $0.02 \mathrm{~nm}$, wavelength division ratio of $0.02 \sim 2 \mathrm{~nm}$ (adjustable), maximum input power $+20 \mathrm{dBm}$, high power sensitivity $-90 \mathrm{dBm}$, wide dynamic range of $70 \mathrm{~dB}$, support singlemode fiber, multimode fiber measurement.

2.2. Principle of Light Pipe. The basic principle of light pipe lighting is to collect outdoor natural light through a light collector, then introduce it into the interior of the system for redistribution, and after that transmit and strengthen it through the special light pipe treatment on the inner wall. Through the diffuser in the indoor part of the system, the processed natural light can be efficiently and evenly used to the places where lighting is needed [24].

2.2.1. Light Collector. The light collector is a component used to collect natural light and is composed of a lighting cover and related accessories. The lighting hood usually adopts a transparent hemispheric shape, and the internal prism structure can collect more sunlight at various angles to ensure the incidence of low-angle sunlight and increase the effective lighting area. The lighting cover of the light collector generally adopts transparent materials that are resistant to ultraviolet rays and impacts [25-27]. At present, there are three types of materials commonly used in lighting hoods: polycarbonate (PC), polymethyl methacrylate (PMMA), and glass. At present, the light collector using PC material has a better effect. The lighting hood can effectively prevent the fading, aging, and other damage caused by ultraviolet radiation to indoor objects, because it can filter out $100 \%$ of ultraviolet rays and nearly $100 \%$ of infrared rays, and can avoid the indoor temperature rise, thereby reducing the load of the air conditioner

2.2.2. Light Guide. The light guide tube is a tubular component used to transmit natural light, and the light guide tube is the core component of the entire light guide tube system. From the perspective of the existing mature products, the light guide tube wall is often made of aluminum material, the inner wall is closer to the mirror effect, and its reflection ratio directly affects the lighting application effect. The light guide tube wall is exposed for a long time, and it is easily affected by cold and hot aging and corrosion during use. Its weather resistance is related to the use function and life of the entire system [28, 29]. There are several types of metal coatings with high reflectance [30], a high-reflectivity film on the inner wall, refraction through efficient optical lenses, and prismatic light guides.

2.2.3. Dimmer. A dimmer is a component used to adjust the light output in a light pipe system. Natural light changes with time, weather, and so on. It is an unbalanced state light. Through the opening and closing of the shading plate, the light flux of the light guide tube is controlled to adjust the light intensity of the indoor space, so that the indoor illuminance reaches a basically stable state. It is mainly composed of an indoor control switch, control circuit, and terminal dimmer [31-33].

\subsection{Research on External Wall Insulation Materials in Building Energy Saving}

2.3.1. External Thermal Insulation Technology. The external insulation of the external wall is to cover the thermal insulation layer on the external surface of the external wall made of masonry or concrete. This external thermal insulation structure can be used not only for the renovation of the existing external wall of the building but also for the construction of new walls. The external wall external insulation technology can obviously improve the thermal insulation energy efficiency of the building. The thermal resistance of the composite wall exceeds $1 \mathrm{~m}^{2} \cdot \mathrm{K} / \mathrm{W}$, and the energy-saving effect is better. And this layer of thermal insulation structure can not only contribute to the stability of the main wall but also meet the relevant requirements of this structure; for example, in order to make the composite external wall able to resist the external collision and cracks, it must be able to meet the wind pressure, watertightness, and temperature and humidity requirements. It is also necessary to properly deal with the coverage methods at the corners, surface decoration, and adjacent parts (e.g., doors, windows, openings, wall pipes) $[34,35]$. For a structure using this insulation technology, the foundation wall must be able to withstand wind and vertical loads and must meet the mechanical stability requirements of the building. It must be safe to use after being subjected to an impact. Only the insulation layer is tightly connected to the main wall, so even if it is impacted, it will not have much impact. The most widely used is flame retardant expanded polystyrene board.

2.3.2. Insulation Technology of External Wall. The inner insulation of the outer wall is to fix the insulation material on the inner side of the outer wall body with an adhesive, and then the outer surface of the insulation material serves as a protective layer and a decorative layer. At present, for internal insulation, polystyrene particles or polystyrene board and other thermal insulation materials are mostly used, and plaster is applied on the outer surface as a surface material. The more commonly used internal insulation technologies are polymer mortar composite polystyrene insulation board, reinforced cement composite polystyrene insulation board, reinforced gypsum composite polystyrene board insulation board, interior wall paste polystyrene board plastering gypsum, and polystyrene particle insulation slurry, plus cracking mortar pressed into the grid cloth [36]. The most widely used is flame retardant expanded polystyrene board.

\subsection{Heat Transfer Characteristics of Phase Change Heat} Storage Composite Wall. The heat storage coefficient of the material reflects the ability of the material to store and release heat under the action of cyclic heat. Its physical meaning is the maximum heat flux density flowing into the surface of the material when the surface temperature 
amplitude is $1^{\circ} \mathrm{C}$. Under the same thermal effect, the larger $S$ is, the smaller the surface temperature fluctuation is and vice versa. $S$ is related not only to the thermal properties of the material $(n, c, \rho)$ but also to the fluctuation period of the external thermal action. The expression formula is

$$
S=\sqrt{\frac{2 \pi \lambda c \rho}{T}}
$$

If it is a composite wall, the heat storage coefficient $S$ of the wall is obtained by weighting the heat storage coefficients of the materials in each layer. Thermal resistance is the most important parameter index to evaluate the wall insulation performance. It represents the total resistance that heat receives from the space on one side of the wall to the space on the other side and reflects the wall's ability to block heat flow. The greater the thermal resistance, the smaller the heat flux density.

The thermal inertia index of the wall reflects the ability of the enclosure structure to resist temperature changes under the action of periodic heat. The capacity is related to the heat storage capacity of the wall. The greater the heat capacity of the envelope, the greater the heat storage capacity and the greater the ability to resist temperature fluctuations.
Therefore, the greater the attenuation of the temperature amplitude, the longer the lag time.

To measure the performance of a single material, the thermal inertia index is the product of its thermal resistance and the heat storage coefficient of the material:

$$
\sum D=D_{1}+D_{2}+\cdots+D_{n} .
$$

As can be seen from the above, if the amplitude of the heat flow wave is constant, the surface heat storage coefficient $S$ of the envelope structure is smaller, and when the amplitude of the heat flow wave is constant, the amplitude of the surface temperature fluctuation is larger, and the thermal stability of the envelope structure is worse. Conversely, the greater the heat storage coefficient $s$ on the surface of the envelope, the smaller the amplitude of surface temperature fluctuations. This indicates that the greater the thermal inertia index $D$ of the envelope, the better the thermal stability.

The delay time is the time delay when the outdoor temperature is transmitted to the inner surface of the wall through the wall, and its formula is

$$
\xi_{0}=\frac{1}{15}\left(40.5 \sum D+\arctan \frac{R_{K} Y_{K i}}{R_{K} Y_{K i}+\sqrt{2}}+\arctan \frac{Y_{e}}{Y_{e}+a_{e} \sqrt{2}}-\arctan \frac{a_{i}}{a_{i}+Y_{i} \sqrt{2}}\right)
$$

The degree of attenuation is a periodic change with the outdoor temperature, and the indoor temperature also changes periodically. However, due to the heat capacity and thermal resistance of the enclosure structure, there is an attenuation in intensity and a delay in time in the change in indoor temperature.

\subsection{Performance Testing and Characterization of Aerogel} Insulation Materials. At present, the commonly used building wall insulation materials are mainly XPS, EPS, polyurethane foam, glass fiber, and other insulation materials. Based on the aerogel insulation materials obtained by the previous research group, the thermal performance is tested and characterized and compared with the performance of commonly used insulation materials, to provide a theoretical basis for the study of the development and application of aerogel insulation materials in building envelopes.

2.5.1. Appearance. The aerogel and aerogel felt samples prepared by the research group were used as thermal insulation materials. The aerogel samples were light blue and had good visible light permeability, but at the same time, the modified and dried pure aerogels could be seen. The overall agglomeration of the rubber material is not good, incomplete, and brittle after compression, which is also the main reason for the poor mechanical properties of pure aerogels. The overall agglomeration of aerogel insulation material after aerogel and glass fiber felt composite is better and complete, and the mechanical properties and strength are obviously better than pure aerogel material; this shows that the addition of fiber can improve its mechanical properties so that it can be easily applied to building envelopes Figure 1.

2.5.2. Infrared Spectral Transmittance. The infrared absorption spectrum of the aerogel powder was tested using a Tensor27 Fourier transform infrared spectrum tester. The infrared spectrum of the aerogel material is shown in Figure 2. It can be seen from the figure that when the wavelength is around $2820 \mathrm{~cm}^{1}$ the $\mathrm{CH}_{3}$ vibration peak has strong vibration at this position, indicating that after the surface is hydrophobically modified, the aerogel has good hydrophobic properties. The $-\mathrm{OH}$ absorption peaks around $1637 \mathrm{~cm}^{-1}$ and $3480 \mathrm{~cm}^{-1}$ are quite weak, which may be because after the sample is hydrophobically modified on the surface, the hydrophilic group (_OH) on the surface of the gel has been replaced by the hydrophobic group $\left(-\mathrm{CH}_{3}\right)$. Therefore, through infrared spectroscopy analysis, aerogel materials have good hydrophobicity. Compared with the hygroscopicity of inorganic thermal insulation materials, the application of aerogel materials on building walls shows good application advantages. 


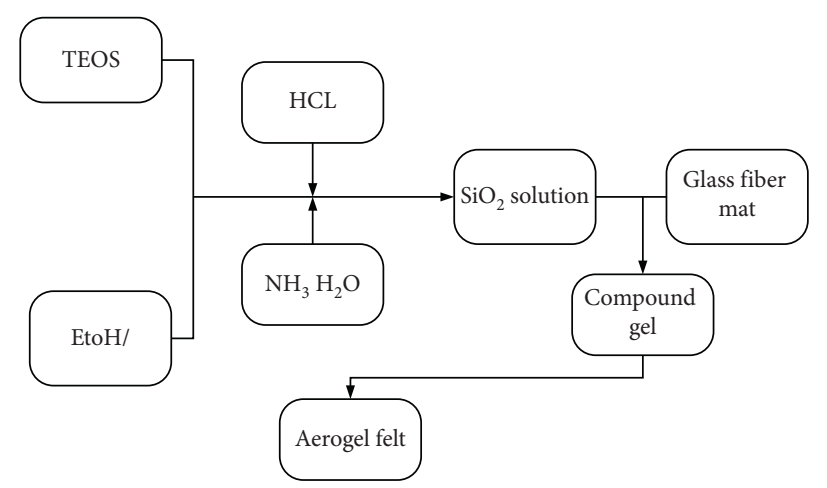

Figure 1: Process flow of aerogel wall insulation material preparation at atmospheric pressure.

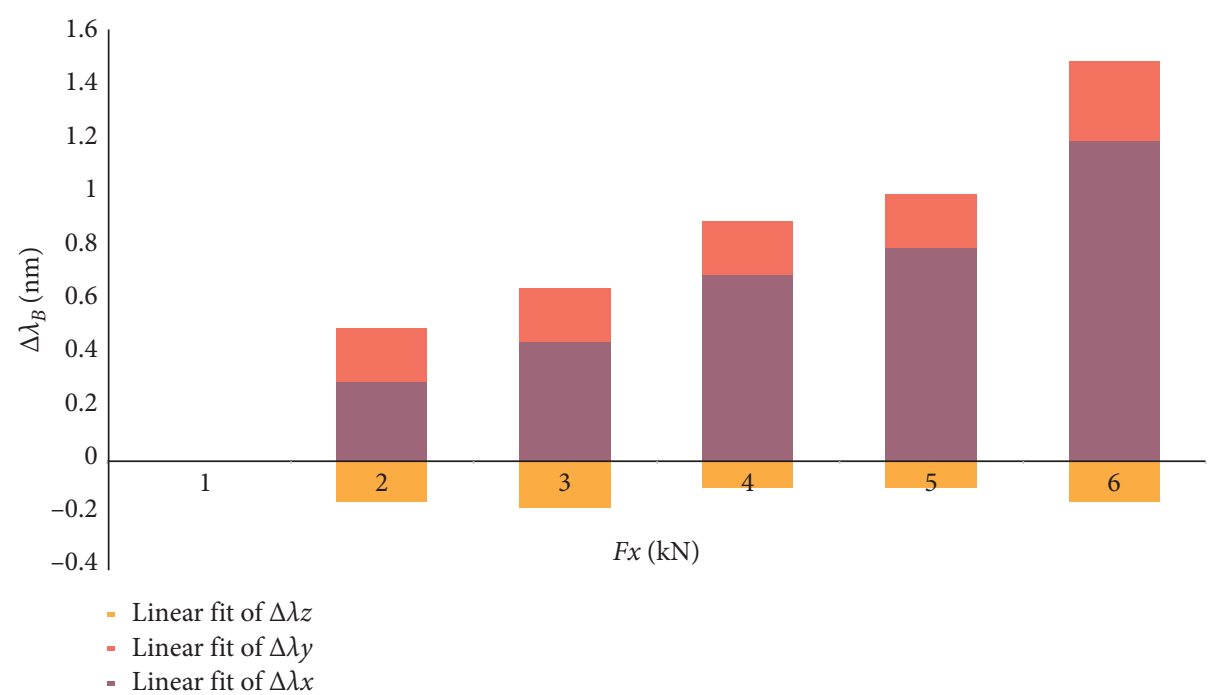

Figure 2: Wavelength of fiber Bragg grating during experimental loading.

\section{Experimental Study on Intelligent Structural System of Civil Engineering}

3.1. Loading Experiment. Load and record the three-dimensional fiber grating sensor riveted on the calibrator. When using a calibrator to load, the compression member will shrink slightly like a concrete structure during the experiment. After the solid loading process is completed, you should wait for the calibrator data to stabilize before reading the wavelength obtained by the spectrometer.

When the sensor is subjected to a uniaxial eccentric load, the center wavelength of the FBG sensor on the corresponding axis will shift. At the same time, the other two FBG sensors will also be affected and displaced. In order to realize the force test of the three-dimensional force sensor in different directions, the pure force $F X, F Y$, and $F Z$ settings have been applied, which can be obtained through the use right. In view of the loading environment in the laboratory, the experimental load was increased from 0 to $5 \mathrm{kN}$ while maintaining the stability of the test temperature.

3.2. Light Guide Design. Two systems of $1.2 \mathrm{~m}$ diameter and $3.85 \mathrm{~m}$ and $3.35 \mathrm{~m}$ length were selected for the design. A light guide tube with a transmission ratio of 0.89 , a light guide tube with a wall reflection ratio of 0.96 , and a diffuser with a transmission ratio of 0.88 are used. The light guide tube lighting device of the underground parking lot is installed in the roof soil layer. From the roof plate to the parking lot ceiling, the entire soil cover layer is passed through. The entire parking lot uses a total of 9 sets of $\mathrm{Cl}$ \# light guide tube systems with a length of $3.85 \mathrm{~m}$ and $11 \mathrm{~A}$ C2\# light pipe system with a length of $3.35 \mathrm{~m}$.

3.3. Experimental Study of Phase Change Materials. This experiment is designed based on JGJ75. When the thermal resistance of the EPS sandwich panel is $0.67 \mathrm{~m}^{2} \cdot \mathrm{K} / \mathrm{W}$, it meets the requirements of JGJ75-2012 50\% energy saving for exterior wall buildings.

Thermal resistance of the wall: experimental design of the wall with three different thicknesses of EPS sandwich panel of $20 \mathrm{~mm}, 25 \mathrm{~mm}$, and $30 \mathrm{~mm}$; that is, the thermal resistance of the sandwich panel is $0.53 \mathrm{~m}^{2} \cdot \mathrm{K} / \mathrm{W}, \quad 0.67 \mathrm{~m}^{2} \cdot \mathrm{K} / \mathrm{W}$, and $0.80 \mathrm{~m}^{2} \cdot \mathrm{K} / \mathrm{W}$ wall. The three temperature adjustment methods designed are as follows: cooling is to reduce the temperature of the cold room from $250{ }^{\circ} \mathrm{C}$ to $15 \%{ }^{\circ} \mathrm{C}$ and to reduce the temperature of the hot room from $55 \%{ }^{\circ} \mathrm{C}$ to $45 \%{ }^{\circ} \mathrm{C}$; heating is to 
increase the temperature of the cold room from $15^{\circ} \mathrm{C}$ to $25 \%{ }^{\circ} \mathrm{C}$, the temperature of the hot room is increased from $45^{\circ} \mathrm{C}$ to $55^{\circ} \mathrm{C}$; and the constant temperature is to keep the temperature of the cold room to $15^{\circ} \mathrm{C}$ and the temperature of the hot room to $55 \%$ C.

3.4. Insulation Material Thickness Selection. This article takes XPS wall insulation material as an example. The payback period for the application of shale hollow brick, aerated concrete, and reinforced concrete is $1.39,4.94$, and 0.54 years, respectively. The investment recovery period and the size of the investment cost are closely related to the price of the insulation material, and the higher the price of the insulation material, the greater the investment recovery period and the greater the total investment cost per unit area. To comprehensively reduce the investment cost and investment recovery period, the thickness and investment cost of new aerogel insulation materials need to be optimized.

\section{Experimental Analysis Based on Civil Engineering Intelligent Structure System}

4.1. Fiber Bragg Grating Design. Tube packaging is the most common method of fiber Bragg grating temperature sensor. It has a variety of forms. There are two main types of structures, that is, sensitized type and nonsensitized type. There are relatively few embedded packaging forms. This packaging method avoids the use of adhesives, reduces the loss of strain transfer, and requires relatively high packaging conditions and equipment. To a certain extent, the loss of strain transmission is reduced, but if there is a large difference between the elastic modulus of the optical fiber and the matrix material, there will be strain transmission loss. In consideration of the accuracy of the experiment, this experiment adopts the sensitization type packaging method.

Commonly used packaging materials include carbon fiber cloth, epoxy resin, copper, concrete, and steel. The corresponding elastic modulus, tensile strength, and other parameters are shown in Table 1.

Comparing the above material properties, we can see that carbon fiber cloth has a higher application value than other materials, its tensile strength is much higher than the other four materials, but its thermal expansion coefficient is far lower than the other four materials, and its superior performance is remarkable. For this paper, since the sensor substrate is a steel structure, it is the primary goal of this paper to ensure that the sensor patch and the steel structure substrate can deform together. Therefore, the use of steel as the packaging material of the sensor can meet the requirements of the experiment to the maximum extent.

When the sensor is subjected to a uniaxial eccentric load, the center wavelength of the FBG sensor on the corresponding axis will shift. At the same time, the other two FBG sensors will also be affected and displaced. In order to realize the force test of the three-dimensional force sensor in different directions, the pure force $F X, F Y$, and $F Z$ settings have been applied, which can be obtained through the use right. In view of the loading environment in the laboratory, the experimental load was increased from 0 to $5 \mathrm{kN}$ while maintaining the stability of the test temperature. In this paper, data analysis and processing were carried out according to the center wavelength record in the experiment. The measurement results in different directions are shown in Figure 2.

The results show that the sensor can accurately and effectively realize the three-dimensional force measurement under external load, with good linearity, repeatability, and consistency. However, due to the manufacturing error and coupling of the sensor, the actual linearity is not as good as the theoretical linearity $[37,38]$. The sensitivity of this sensor is $0.255 \mathrm{~nm} / \mathrm{kN}, 0.256 \mathrm{~nm} / \mathrm{kN}$, and $0.256 \mathrm{~nm} /$ $\mathrm{kN}$, respectively. They are slightly different and smaller than the simulation results, which may cause operation errors caused by the sensor packaging and experiment. Experimental results and analysis studies have proved that the three-dimensional force sensor based on the multiplexed FBG strain sensor has high accuracy.

By analyzing the experimental data, it can be concluded that there is a certain coupling of the three-way strain within $1 \mathrm{kN}$, but after the loading force exceeds $1 \mathrm{kN}$, the three-way strain has good linearity, and the other two-way strains follow the axial strain. The increase of the loading force gradually tends to a fixed value.

4.2. Experimental Study and Analysis of the Application Effect and Subjective Feeling of the Light Guide Lighting. The objects selected in this paper are the well-known projects in the main regions. Such projects are well-known, and the application of light guides may not be derived from the green energy saving in the surface sense, but the role and effect of light guides. Combining with your own projects, give full play to the lighting effect of the light guide tube, and at the same time, the social responsibility and quota are also high. It shows the current situation of the light environment to the greatest extent and has a representative and practical reference value for research. In this paper, the two representative light guide tube projects selected for testing are selected, as shown in Table 2.

During the investigation, the author found that the utilization rate of the venue is very high, there are people who come to exercise continuously, and the users can maintain a happy mood with each other. During the investigation, the author has not heard of the situation of the impact of playing due to light. The entire light environment gives a bright feeling, but during the test, the author clearly felt that there would be no glare when looking up at the light guide lighting, and artificial lighting did produce glare. The whole test process continued for 3 hours because the author needed to look up at the position of artificial lighting to determine the location of the measuring point. The author had a slight headache and dizziness.

Question: Do you think that the light pipe can meet your lighting needs during the sunny day? The question is mainly to consider whether the light pipe lighting can get rid of the cooperation with artificial lighting when it is sunny Figure 3.

More than $50 \%$ of the two projects think that it is generally satisfactory; in addition, $30 \%$ think it can be 
TABLE 1: List of different material properties.

\begin{tabular}{lccc}
\hline Material type & Modulus of elasticity $(\mathrm{GPa})$ & Tensile strength $(\mathrm{MPa})$ & Thermal expansion coefficient \\
\hline Carbon fiber cloth & $220-245$ & $3200-6182$ & $-0.86-0.87$ \\
Epoxy resin & $\times$ & $\times$ & $87-93$ \\
Copper & 132 & $254-328$ & 18.4 \\
Concrete & $24-31$ & $\times$ & $11-17$ \\
Steel & 210 & $320-384$ & 13 \\
\hline
\end{tabular}

TABLE 2: Details of sample light pipe lighting project.

\begin{tabular}{lccccc}
\hline Project name & Number of applications & Application time & Application & Application height & Main business \\
\hline Stadium & 154 & 2017 & Stadium & 19 & Event \\
University parking lot & 24 & 2018 & Underground parking lot & 4.8 & Public parking \\
\hline
\end{tabular}

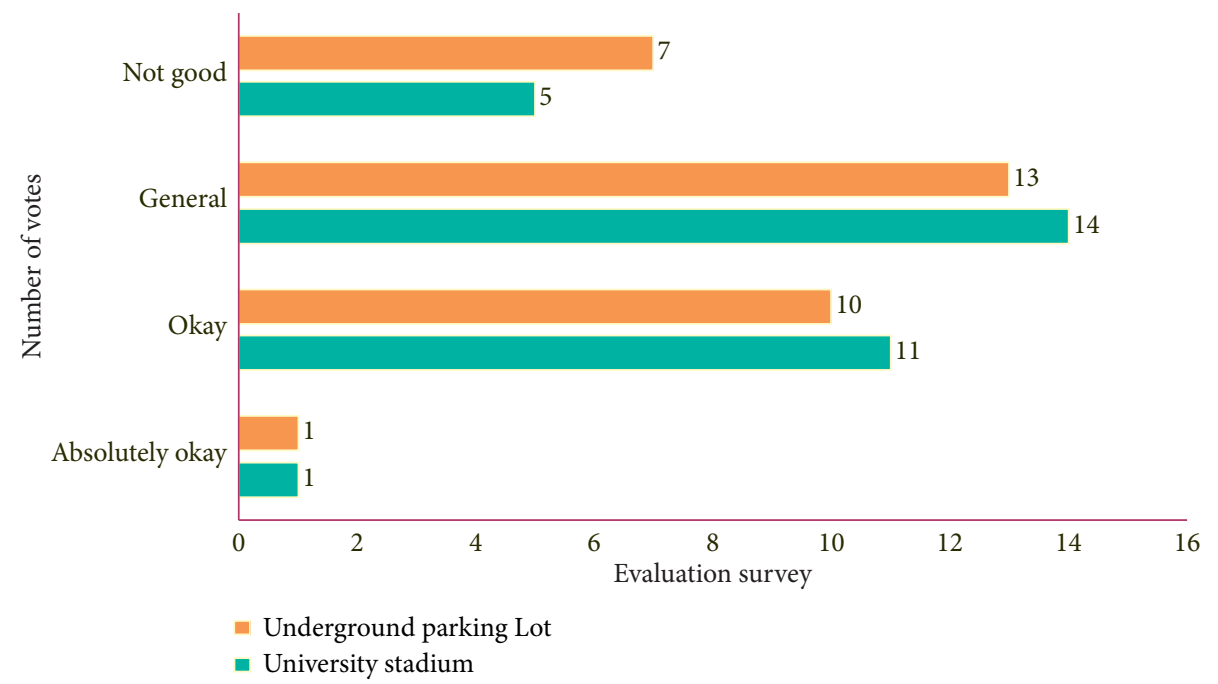

FIGURE 3: Research on subjective feelings of light guide tube lighting application status.

satisfied, $10 \%$ think it cannot be met, $3 \%$ think it can be met and meet the light guide during sunny daytime. The recognition of lighting needs is the same as the selection ratio of the two projects, which means that the light guide can meet the needs of people under certain good lighting and use conditions

\subsection{Energy-Saving Effect of Different Thermal Resistance} Walls. The composition of the wall from the cold room to the hot room is as follows: phase change plate +EPS plate + inorganic plate. In the case where the phase change material dosage is $2 \mathrm{~kg} / \mathrm{m}^{2}$, only change the thickness of the sandwich panel, test the heat transfer coefficient of the wall under the three temperature adjustment methods, and find the average value, which is the same as that under the same conditions. The measured heat transfer coefficients of the walls mixed with the phase change material are compared, and the energy-saving effect of the walls mixed with the phase change material is calculated according to the above energy-saving effect. The experiment is shown in Figure 4.

Figure 4 shows the energy-saving effect of different thermal resistance walls. It can be seen from Figure 4 that, as the thickness of the sandwich EPS board increases, the energy-saving effect of the wall increases, which is due to the increase in the heat storage effect of the phase change material as the thermal resistance of the wall increases. However, when the thickness of the sandwich panel is $30 \mathrm{~mm}$, the increase in energy-saving effect decreases, which is almost equal to the energy-saving effect when the thickness of the sandwich panel is $25 \mathrm{~mm}$. It can be seen that the thickness of the sandwich panel is better, the phase change thickness and the material of the sandwich panel have the best combination. It can be seen that when the thickness of the sandwich panel is $25 \mathrm{~mm}$, it is the optimal insulation layer thickness.

4.4. Fire Protection and Mechanical Properties. Since the insulation material is installed on the outer surface of the base wall, not only the room temperature insulation performance of the insulation material but also the fire resistance and flame retardant performance of the aerogel insulation material at high temperature needs to be considered, and the outdoor environmental conditions will also be analyzed. Affecting its stress condition, the mechanical properties of the insulation materials also need to be comprehensively compared. Figure 5 shows the temperature variation of the same thickness of glass fiber and aerogel 


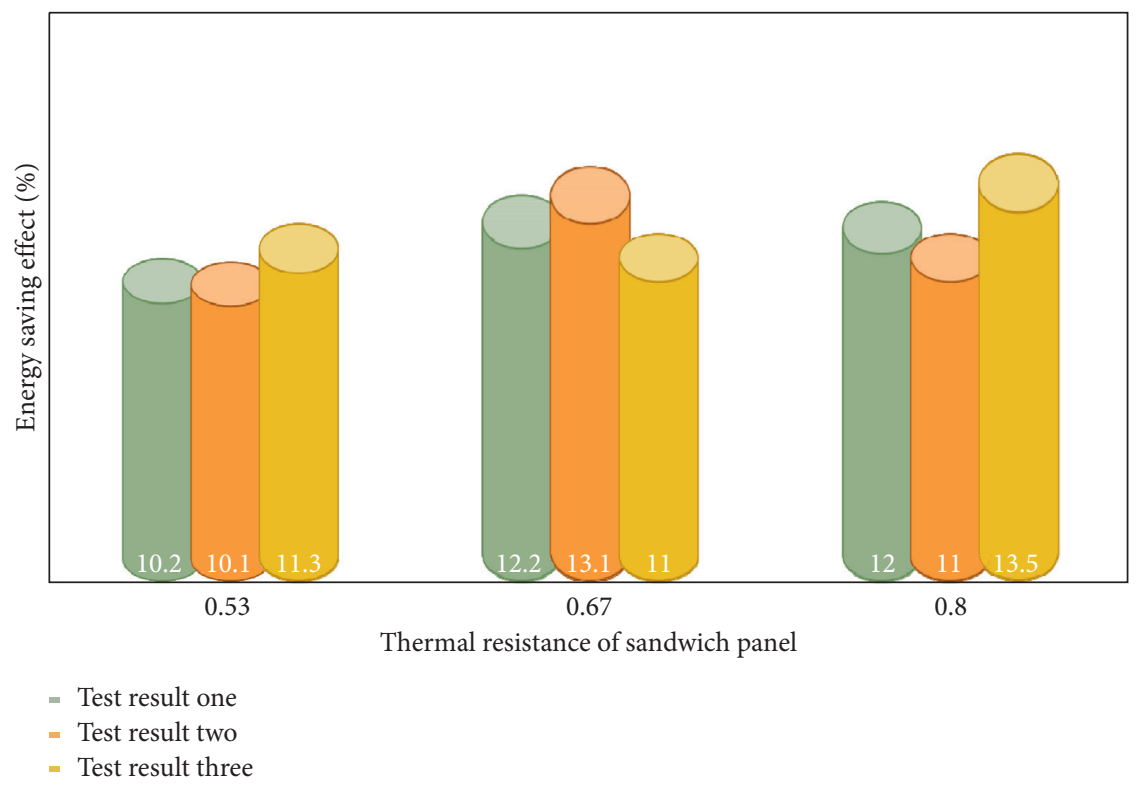

Figure 4: Energy-saving effects of different thermal resistance walls.

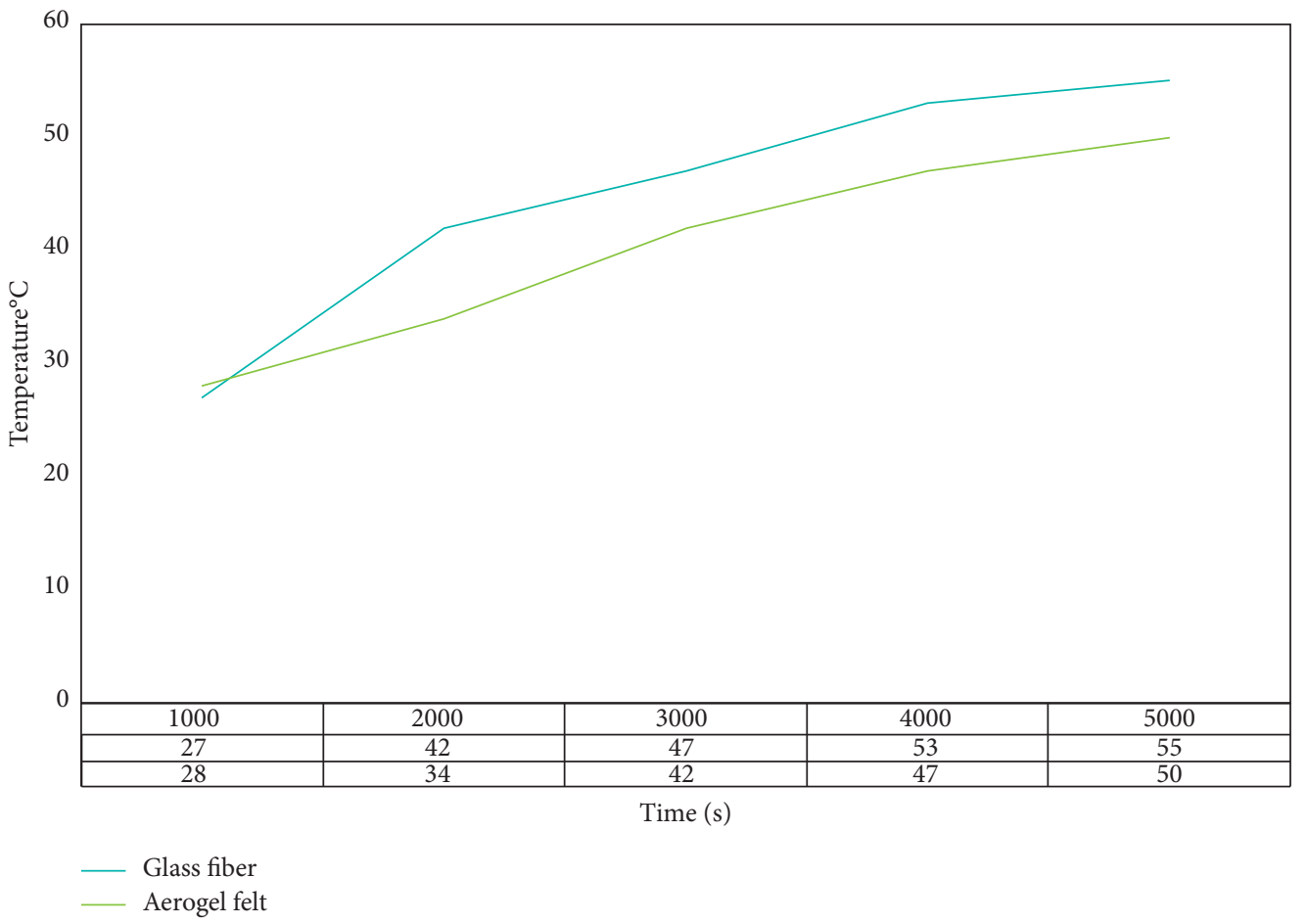

FIGURE 5: Variation curve of the test temperature of the concrete slab with time.

insulation materials applied to the side of the $20 \mathrm{~mm}$ concrete slab with time.

It can be seen from Figure 5 that the temperature of the side of the concrete slab with glass fiber wool increases faster, and the temperature of the side of the concrete slab with aerogel insulation material rises more slowly. When the temperature rises from $30^{\circ} \mathrm{C}$ to $50^{\circ} \mathrm{C}$, add the time required for the fiberglass mat and aerogel insulation material on the concrete slab side is about 2020 and 3390 s, respectively, indicating that the aerogel insulation material has significantly better fire performance than glass fiber.

\section{Conclusions}

This paper studies the factors that affect the economic performance of aerogel wall insulation materials. The results show that, with the increase of degree days, the economic thickness of insulation materials increases linearly, the 
investment recovery period decreases linearly, the aerogel insulation materials have also changed. The degree is more obvious than the commonly used insulation materials; as the thermal resistance of the base wall increases, the economic thickness decreases linearly, and the investment recovery period increases linearly. While as the price of the aerogel insulation material decreases, the economic thickness and economic benefits. With the increase, the total investment cost, payback period, and greenhouse gas emissions all decrease, indicating that the new aerogel wall insulation materials have significant economic and environmental benefits after the price continues to decrease, reducing the price of aerogel materials. It is an important driving force to promote the energy-saving construction of aerogel insulation materials.

In this paper, aerated concrete blocks are used as the basic wall of the wall material. In the case of external protection stickers and internal insulation mortar, it can meet the requirements of 50\% energy saving for external wall buildings. Compared with the benchmark wall of $50 \%$ energy saving of exterior wall buildings, the heat transfer coefficient is reduced by $50.1 \%$ when the exterior decoration stickers are applied and the phase change mortar is applied inside. The actual energy-saving effect of the wall can reach $75 \%$. The requirement of wall building energy-saving effect is $65 \%$. When the phase change mortar is applied on both the inside and the outside, the heat transfer coefficient is reduced by $29.85 \%$ compared with the benchmark wall of $50 \%$ energy saving of the external wall building, and the actual energysaving effect of the wall can reach $65 \%$, meeting the energy saving of external wall building $65 \%$ effect requirement.

This paper completes the construction work of the fiber grating sensor monitoring platform based on the sensor and carries out experimental design and data collection work, comprehensively judging the structural deformation and the output of the fiber grating sensor under the axial and multidirectional force. The waveform of the structure can be analyzed according to the waveform, and, finally, the stressstrain diagram of the structure to be measured is obtained, so that the real-time monitoring of the building structure can be realized, and then the specific location of the fault can be judged.

\section{Data Availability}

All the data are available.

\section{Conflicts of Interest}

The authors declare that they have no conflicts of interest.

\section{References}

[1] S.-B. Tsai, "Using grey models for forecasting China's growth trends in renewable energy consumption," Clean Technologies and Environmental Policy, vol. 18, no. 2, pp. 563-571, 2016.

[2] C. Li, F. Sun, J. M. Cioffi, and L. Yang, "Energy efficient MIMO relay transmissions via joint power allocations," IEEE Transactions on Circuits and Systems II: Express Briefs, vol. 61, no. 7, pp. 531-535, 2014.
[3] D. Legatiuk, K. Dragos, and K. Smarsly, "Modeling and evaluation of cyber-physical systems in civil engineering," PAMM, vol. 17, no. 1, pp. 807-808, 2017.

[4] M. Chowdhury and K. Dey, "Intelligent transportation systems-a frontier for breaking boundaries of traditional academic engineering disciplines [education]," IEEE Intelligent Transportation Systems Magazine, vol. 8, no. 1, pp. 4-8, 2016.

[5] S. Manandhar, K. Miyazoe, S. Fukuoka et al., "Observation of static load of L-shaped retaining wall constructed on short wooden pile using fiber optic geogrid BOTDR method," Indian Geotechnical Journal, vol. 46, no. 4, pp. 1-10, 2016.

[6] H. Zhang and J. Li, "Modeling and dynamical topology properties of VANET based on complex networks theory," Aip Advances, vol. 5, no. 1, pp. 1538-1556, 2015.

[7] S. Abubaker, S. Nagan, and T. Nasar, "Intelligent control of semi active tuned liquid column damper with structure," International Journal of Applied Engineering Research, vol. 10, no. 55, pp. 3579-3582, 2015.

[8] S. Qu, L. Zhao, and Z. Xiong, "Cross-layer congestion control of wireless sensor networks based on fuzzy sliding mode control," Neural Computing and Applications, vol. 32, pp. 13505-13520, 2020.

[9] J. Zhao, J. Jin, J. Zhu et al., "Water resources risk assessment model based on the subjective and objective combination weighting methods," Water Resources Management, vol. 30, no. 9, pp. 3027-3042, 2016.

[10] R. C. Barros and M. T. Braz-Cesar, "Semi-Active fuzzy based control system for vibration reduction of a SDOF structure under seismic excitation," Smart Structures \& Systems, vol. 21, no. 4, pp. 389-395, 2018 .

[11] Y. Cheng, Y. Chen, R. Wei et al., "Development of a construction quality supervision collaboration system based on a SaaS private cloud," Journal of Intelligent \& Robotic Systems, vol. 79, no. 3-4, pp. 613-627, 2015.

[12] F. Tommaso, A. Antonio, D. S. Riccardo et al., "Numerical simulation of oil jet lubrication for high speed gears," International Journal of Aerospace Engineering, vol. 2015, Article ID 752457, 13 pages, 2015.

[13] C. D. Supraja, R. G. Reddy, T. Kalyani et al., "Sols technique based encoder for dedicated short range communication in intelligent transportation system applications," International Journal of Civil Engineering and Technology, vol. 8, no. 8, pp. 1197-1202, 2017.

[14] L. Wang, P. Sun, M. Xie et al., "Advanced driver-assistance system (ADAS) for intelligent transportation based on the recognition of traffic cones," Advances in Civil Engineering, vol. 2020, no. 4, Article ID 8883639, 8 pages, 2020.

[15] Y. R. V. S. Chandra, M. S. Harun, and T. Reshma, "Intelligent transport system," International Journal of Civil Engineering and Technology, vol. 8, no. 4, pp. 2230-2237, 2017.

[16] M. V. A. Florea and H. J. H. Brouwers, "Treatment of incineration by-products for generating new building materials," Acta Neurochirurgica, vol. 153, no. 5, pp. 1021-1022, 2015.

[17] N. N. Klimenko, I. Yu Kolokol'chikov, N. Y. Mikhailenko et al., "New high-strength building materials based on metallurgy wastes," Glass and Ceramics, vol. 75, no. 5-6, pp. 206-210, 2018.

[18] I. Kitouni, D. Benmerzoug, and F. Lezzar, "Smart agricultural enterprise system based on integration of internet of things and agent technology," Journal of Organizational and End User Computing, vol. 30, no. 4, pp. 64-82, 2018.

[19] C. Nuccetelli, Y. Pontikes, F. Leonardi, and R. Trevisi, "New perspectives and issues arising from the introduction of 
(NORM) residues in building materials: a critical assessment on the radiological behaviour," Construction and Building Materials, vol. 82, pp. 323-331, 2015.

[20] A. Bracht, "Successful 14th NCB international seminar on cement and building materials in New Delhi," ZKG International, vol. 69, no. 1-2, pp. 14-15, 2016.

[21] C. Li, P. Liu, C. Zou, F. Sun, J. M. Cioffi, and L. Yang, "Spectral-efficient cellular communications with coexistent one-and two-hop transmissions," IEEE Transactions on Vehicular Technology, vol. 65, no. 8, pp. 6765-6772, 2015.

[22] M. Weng, Z. Wang, G. Qian et al., "Identify crystal structures by a new paradigm based on graph theory for building materials big data," Science China Chemistry, vol. 62, no. 8, pp. 982-986, 2019.

[23] S. R. Bhatta, K. Tiippana, K. Vahtikari, P. Kiviluoma, M. Hughes, and M. Kyttä, "Quantifying the sensation of temperature: a new method for evaluating the thermal behaviour of building materials," Energy and Buildings, vol. 195, pp. 26-32, 2019.

[24] X. Sun, Q. Zhang, M. A. Medina, K. O. Lee, and S. Liao, "Parameter design for a phase change material board installed on the inner surface of building exterior envelopes for cooling in China," Energy Conversion and Management, vol. 120, pp. 100-108, 2016.

[25] X. Long, W. Zhang, Y. Li, and L. Zheng, "Thermal performance improvement of lightweight buildings integrated with phase change material: an experimental and simulation study," Advances in Mechanical Engineering, vol. 9, no. 6, 2017.

[26] K. G. Srinivasa, B. J. Sowmya, A. Shikhar, R. Utkarsha, and A. Singh, "Data analytics assisted internet of things towards building intelligent healthcare monitoring systems: iot for healthcare," Journal of Organizational and End User Computing, vol. 30, no. 4, pp. 83-103, 2018.

[27] F. Kuznik, K. Johannes, E. Franquet et al., "Impact of the enthalpy function on the simulation of a building with phase change material wall," Energy and Buildings, vol. 126, pp. 220-229, 2016.

[28] T. Akihiro and S. Hirotaka, "Development of evaluation method of daylighting duct system considering inner light flux," Computer Aided Drafting Design \& Manufacturing, vol. 25, no. 04, pp. 5-11, 2015.

[29] E. K. W. Tsang, M. Kocifaj, D. H. W. Li, F. Kundracik, and J. Mohelníková, “Straight light pipes' daylighting: a case study for different climatic zones," Solar Energy, vol. 170, pp. 56-63, 2018.

[30] G. Bo, L. Chang, H. Chenglong et al., "Effect of Mg and RE on the surface properties of hot dipped Zn-23Al-0.3Si coatings," Science of Advanced Materials, vol. 11, no. 4, pp. 580-587, 2019.

[31] S.-B. Tsai, M.-F. Chien, Y. Xue, and L. Li, "Using the fuzzy dematel to determine environmental performance: a case of printed circuit board industry in taiwan," PLoS One, vol. 10, no. 6, Article ID e0129153, 2015.

[32] S. K. Biswas, D. Devi, and M. Chakraborty, "A hybrid case based reasoning model for classification in internet of things (iot) environment," Journal of Organizational and End User Computing, vol. 30, no. 4, pp. 104-122, 2018.

[33] M. R. Reddy, K. G. Srinivasa, and B. E. Reddy, "Smart vehicular system based on the internet of things," Journal of Organizational and End User Computing, vol. 30, no. 3, pp. 45-62, 2018.
[34] Z.-h. Liu, Y.-d. Ding, F. Wang, and Z.-p. Deng, "Thermal insulation material based on $\mathrm{SiO} 2$ aerogel," Construction and Building Materials, vol. 122, pp. 548-555, 2016.

[35] U. Berardi and L. Ákos, "Thermal bridges of metal fasteners for aerogel-enhanced blankets," Energy and Buildings, vol. 185, pp. 307-315, 2019.

[36] M. Abdel-Basset, R. Mohamed, M. Elhoseny, and V. Chang, "Evaluation framework for smart disaster response systems in uncertainty environment," Mechanical Systems and Signal Processing, vol. 145, 2020.

[37] R. Parada, J. Melià-Seguí, and R. Pous, "Anomaly detection using rfid-based information management in an iot context," Journal of Organizational and End User Computing, vol. 30, no. 3, pp. 1-23, 2018.

[38] K. Shi, J. Wang, S. Zhong, Y. Tang, and J. Cheng, "Hybriddriven finite-time $H \infty$ sampling synchronization control for coupling memory complex networks with stochastic cyber attacks," Neurocomputing, vol. 387, pp. 241-254, 2020. 